Article

\title{
Operating Safety Evaluation of Battery-Electric Taxi Based on Spatio-Temporal Speed Parameters
}

\author{
Xueyu Mi ${ }^{1,2}$, Chunjiao Dong ${ }^{1, *(\mathbb{D}}$, Ning $\mathrm{Li}^{1}, \mathrm{Yi} \mathrm{Lin}^{3}$, Chunfu Shao ${ }^{1}$ and Bosong Fan ${ }^{1}$ \\ 1 Key Laboratory of Transport Industry of Big Data Application Technologies for Comprehensive Transport, \\ Ministry of Transport, Beijing Jiaotong University, Beijing 100044, China; 14114209@bjtu.edu.cn (X.M.); \\ 20125744@bjtu.edu.cn (N.L.); cfshao@bjtu.edu.cn (C.S.); fanbosong@bjtu.edu.cn (B.F.) \\ 2 College of Civil and Architectural Engineering, North China University of Science and Technology, \\ Tangshan 063210, China \\ 3 Road Construction Project Management Center of Beijing Municipal Bureau of Road Administration, \\ Beijing 100044, China; linyi01ly@sina.com \\ * Correspondence: cjdong@bjtu.edu.cn; Tel.: +86-010-51684589
}

check for

updates

Citation: Mi, X.; Dong, C.; Li, N.; Lin, Y.; Shao, C.; Fan, B. Operating Safety Evaluation of Battery-Electric Taxi Based on Spatio-Temporal Speed Parameters. Sustainability 2021, 13, 13446. https://doi.org/10.3390/ su132313446

Academic Editors: Xiaobei Jiang,

Haixiang Lin, Fei Yan and

Qian Cheng

Received: 14 October 2021

Accepted: 2 December 2021

Published: 4 December 2021

Publisher's Note: MDPI stays neutral with regard to jurisdictional claims in published maps and institutional affiliations.

Copyright: (c) 2021 by the authors. Licensee MDPI, Basel, Switzerland. This article is an open access article distributed under the terms and conditions of the Creative Commons Attribution (CC BY) license (https:/ / creativecommons.org/licenses/by/ $4.0 /)$.

\begin{abstract}
The battery-electric taxis have the features of larger mass, low operating noise, and great speed, and the drivers of battery-electric taxis have various driving behaviors and low safety awareness, which leads to higher safety risks. In the paper, the driving and speed characteristics of battery-electric taxis, conventional taxis, and private cars are compared and analyzed through conducting a GPS trajectory survey and a cross-section traffic flow parameter survey. An evaluation index system that is based on the spatio-temporal speed parameters is proposed, and a MEW-VIKOR method is developed for the operatiing safety evaluation of the battery-electric taxi. The results show that the operating speed of battery-electric taxis is significantly higher than that of conventional taxis on weekdays and weekends, and there is a relatively common speeding phenomenon on urban local roads. The proposed safety evaluation index system that is based on the spatio-temporal speed parameters and the MEW-VIKOR evaluation method can effectively evaluate the operatiing safety of battery-electric taxis. In addition, the ranking results show that, according to the spatio-temporal speed parameters, the operating safety of battery-electric taxis is lower than that of conventional taxis and private cars. The research provides theoretical insights for strategies and policies making to reduce the unsafe driving behaviors of battery-electric taxis.
\end{abstract}

Keywords: urban traffic; battery-electric taxi; spatio-temporal speed parameter; MEW-VIKOR method

\section{Introduction}

In 2012, "The Development Plan for Energy Conservation and New Energy Automobile Industry (2012-2020)" was issued by the Chinese government, which clearly defines the new energy battery-electric vehicles as one of the ten strategic emerging industries and a strategic direction for the transformation of the automotive industry. As a new type of green vehicle, electric vehicles (EVs) are often seen as a promising technology for reducing the external costs of road transport [1-3], and thus the battery-electric vehicles are used more often and more widely. A huge number of battery-electric vehicles and their unique traffic characteristics pose a great challenge to traffic managers, and the electric vehicles' operational safety (EVOS) is becoming an important issue [4,5]. For example, the lack of engine noise to warn people of oncoming electric or hybrid vehicles leads to safety issues for pedestrians and cyclists [6,7]. Lee developed a method to evaluate the sound quality of the warning sound masked by background noise, considering the masking effect. [8] Statistics on road traffic accidents in recent years show that the number of traffic accidents and fatalities related to battery-electric vehicles have increased to a certain degree $[9,10]$. The frequent occurrences of traffic accidents involving battery-electric vehicles, especially battery-electric taxis, are caused by multiple factors. In addition to their increasing entry onto the market, battery-electric taxis have different speed parameter distribution 
characteristics compared with other conventional taxis and private cars, as well as the objective factors, such as unreasonable traffic design and the unscientific development of the road traffic environment. In particular, the overall great mass of battery-electric taxis significantly reduces their safety features.

Previous research mainly focuses on the impacts of battery power fire and highvoltage electric shock on the usage safety of battery-electric vehicles. The research on the operating safety of battery-electric vehicles from the perspective of speed parameters is lacking [11-13]. Cao [14] studied the safety of the electric vehicle power system and the vehicle as a whole, and established an evaluation method for the safety of the electric vehicle power system. The research provided a basis for improving the safety of electric vehicles. Abdurahim Mukiyt et al. [15] established an electric vehicle safety evaluation index system with braking safety, driving and steering safety, battery safety, electrical safety, and auxiliary system safety as the secondary indicators, and evaluated the safety of electric vehicles by using a fuzzy-analytic hierarchy process and an expert-scoring weight calculation method. Zhang [16] developed a comprehensive evaluation model for batteryelectric vehicles using a hierarchical analysis with power and economy as the evaluation objectives. The cell-to-cell variations in battery power may lead to battery failure and cause safety problems. Lu [17] proposed a method to assess inter-cell variation in lithiumion batteries based on charging cloud data. In addition, Concha [18] studied the effect of the magnetic field of electric vehicle batteries on passengers. Zhu [19] investigated real-time battery thermal management strategies for vehicles, presenting a detailed assessment of the most common reaction mechanisms, identifying differences between each in terms of decomposition and formation reactions.

Letty [20] proposed that driving speed is an important factor affecting road safety. Hence, in order to promote the development of urban traffic and to ensure the safety and smooth travel of the public [21], it is necessary to perform an evaluation of the operating safety of battery-electric taxis based on the speed parameters. The batteryelectric taxis, as an important part of public transportation, are critical for enhancing traffic safety. The research results can provide technical support for making urban traffic safety countermeasures and driving behavior management policies.

To evaluate the operating safety of electrical taxis from the perspective of speed factors, six tasks have been conducted and performed. Section 1 introduces the background, significance, and relevant literature review. In Sections 2 and 3, the speed characteristics of battery-electric taxis based on GPS data and radar gun data are analyzed. In Section 4, 15 indicators and a MEW-VIKOR evaluation method are developed to assess the operating safety of battery-electric taxis. Considering the ranking results of battery-electric taxis, conventional taxis, and private cars, Section 5 proposes a further investigation that examines the collision between the electrical taxis and pedestrians with an assumed speed that has been shown to comprehensivly address the safety issue of the electrical taxi. The last section of the paper is the conclusion, which mainly describes the main conclusions and research findings.

\section{Speed Characteristics of Battery-Electric Taxis Based on GPS Data}

In order to obtain the driving features and speed characteristics of battery-electric taxis, 140 battery-electric taxi drivers were selected and on-board GPS devices were installed in the battery-electric taxis. In January 2019, the speed and location information of the battery-electric taxis were collected. At the same time, the GPS trajectory data from conventional taxis were also collected; the conventional taxi in the research refers to the internal combustion taxi. The data formats are shown in Table 1. 
Table 1. GPS data structure of battery-electric taxis.

\begin{tabular}{cccccccc}
\hline INDEX & DATE & TIME & LATITUDE N/S & LONGITUDE E/W & HEIGHT & SPEED & HEADING \\
\hline 6110 & 190122 & 6 & $22.600058 \mathrm{~N}$ & $113.843754 \mathrm{E}$ & 14 & 52.5 & 155 \\
57378 & 190122 & 144655 & $22.520761 \mathrm{~N}$ & $113.913791 \mathrm{E}$ & -4 & 0 & 297 \\
88795 & 190122 & 235951 & $22.546731 \mathrm{~N}$ & $114.091021 \mathrm{E}$ & 12 & 49.5 & 179 \\
252237 & 190125 & 0 & $22.598066 \mathrm{~N}$ & $114.302528 \mathrm{E}$ & 10 & 4.3 & 228 \\
252773 & 190125 & 1034 & $22.582491 \mathrm{~N}$ & $114.249229 \mathrm{E}$ & 33 & 68.8 & 310 \\
\hline
\end{tabular}

Note: The data were obtained from the trajectories of taxis.

According to the collected data, the starting performance, braking performance, and operating characteristics of the battery-electric taxi on the weekdays and weekends were analyzed from the perspectives of acceleration, deceleration, and travel speed.

The mean acceleration and deceleration characteristics of battery-electric taxis on weekdays and weekends are shown in Figure 1. According to Figure 1, the average acceleration and deceleration values of battery-electric taxis are significantly higher than those of conventional taxis during both weekdays and weekends, regardless of off-peak hours and peak hours, indicating that the operating stability of battery-electric taxis is poor.

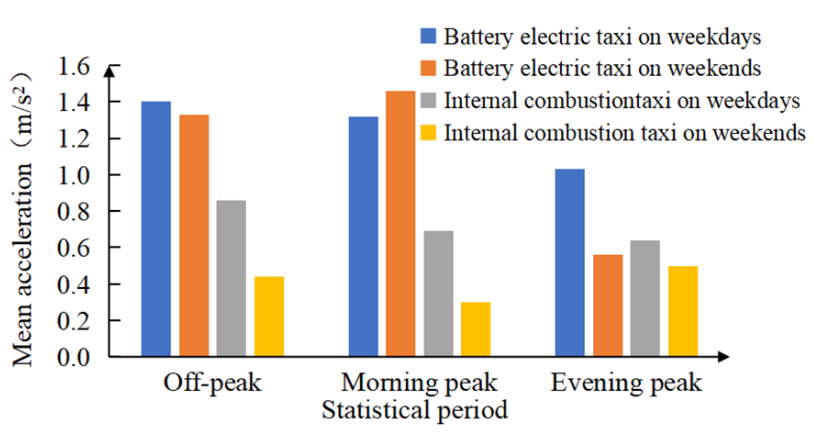

(a)

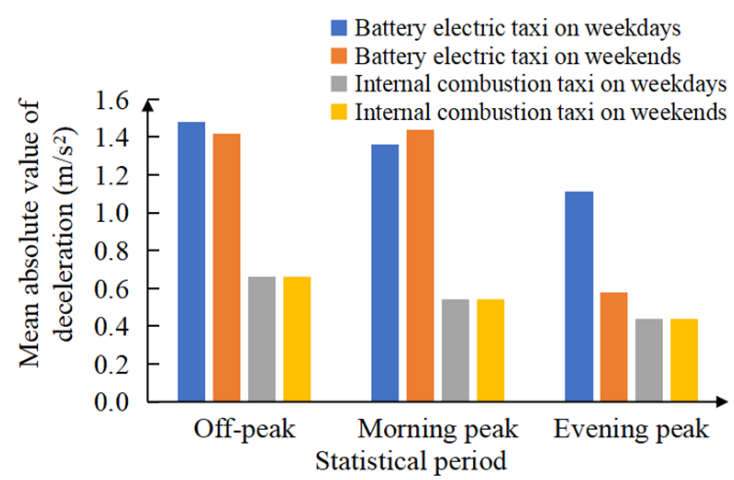

(b)

Figure 1. Comparison of acceleration and deceleration characteristics between battery-electric taxis and conventional taxis. (a) Acceleration characteristics; (b) Deceleration characteristics.

The operating speed characteristics of battery-electric taxis and conventional taxis on weekdays and weekends were compared and analyzed, and the results are shown in Table 2. Table 2 shows that on both weekdays and weekends, regardless of off-peak hours and peak hours, the average speed and variance of battery-electric taxis were significantly higher than that of conventional taxis, indicating the aggressive driving behavior induced by the acceleration and deceleration characteristics of battery-electric taxis.

Table 2. Operating speed characteristics of battery-electric taxis and conventional taxis $(\mathrm{km} / \mathrm{h})$.

\begin{tabular}{ccccccccc}
\hline \multirow{2}{*}{ Operating Speed } & \multicolumn{4}{c}{ Battery-Electric Taxi } & \multicolumn{3}{c}{ Conventional Taxi } \\
\cline { 2 - 10 } & \multicolumn{2}{c}{ Weekdays } & \multicolumn{2}{c}{ Weekends } & \multicolumn{2}{c}{ Weekdays } & \multicolumn{2}{c}{ Weekends } \\
\cline { 2 - 9 } & Mean & Variance & Mean & Variance & Mean & Variance & Mean & Variance \\
\hline Off-peak & 60.57 & 611.12 & 60.57 & 611.12 & 20.38 & 54.47 & 19.44 & 33.96 \\
Morning peak & 54.55 & 429.46 & 54.55 & 429.46 & 19.86 & 62.97 & 17.92 & 45.58 \\
Evening peak & 45.86 & 701.60 & 45.86 & 701.60 & 20.08 & 30.19 & 19.34 & 28.09 \\
\hline
\end{tabular}

Note: The data are obtained from the trajectories of taxis. 


\section{Speed Characteristics of Battery-Electric Taxis Based on Radar Gun Data}

To further analyze the space-speed characteristics of battery-electric taxis, a total of eight roads, including three major arterial roads, three minor arterial roads, and two local roads were selected, and eight speed observation points were set up to collect the instantaneous speed of battery-electric taxis and private cars by using the handheld radar gun [22]. The locations of the investigated road sections and observation points are shown in Figure 2. According to the collected instantaneous speed of the vehicles, the speed characteristics of battery-electric taxis and private cars were analyzed according to the indicators of road grade and speed limit. The results are shown in Table 3.

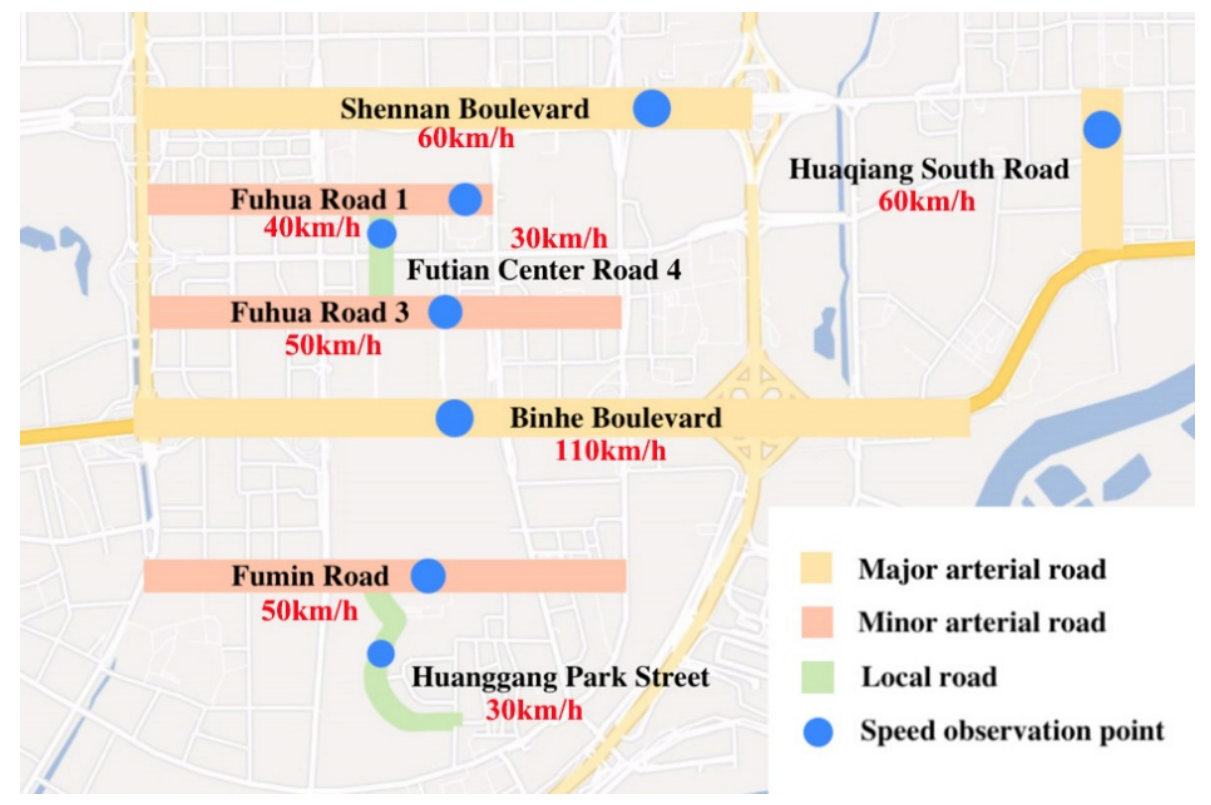

Figure 2. The location of the speed observation points.

Table 3. Speed characteristics of battery-electric taxis and private cars based on radar gun data.

\begin{tabular}{cccccccccc}
\hline \multirow{2}{*}{ Road Grade } & $\begin{array}{c}\text { Limit Speed } \\
\mathbf{( k m / h )}\end{array}$ & $\begin{array}{c}\text { Speed } \\
\text { Sample }\end{array}$ & $\begin{array}{c}\text { Mean } \\
\text { Speed }\end{array}$ & $\begin{array}{c}\text { Speeding } \\
\text { Sample }\end{array}$ & $\begin{array}{c}\text { Speeding } \\
\text { Ratio } \mathbf{( \% )}\end{array}$ & $\begin{array}{c}\text { Speed } \\
\text { Sample }\end{array}$ & $\begin{array}{c}\text { Mean } \\
\text { Speed }\end{array}$ & $\begin{array}{c}\text { Speeding } \\
\text { Sample }\end{array}$ & $\begin{array}{c}\text { Speeding } \\
\text { Ratio (\%) }\end{array}$ \\
\hline Major arterial & 110 & 175 & 61.59 & 0 & 0 & 225 & 60.18 & 0 & 0 \\
road & 60 & 136 & 52.64 & 19 & 13.97 & 176 & 56.64 & 22 & 12.50 \\
Minor arterial & 50 & 175 & 38.13 & 13 & 7.43 & 119 & 38.55 & 12 & 10.08 \\
$\quad$ road & 40 & 37 & 32.76 & 0 & 0 & 83 & 35 & 20 & 24.10 \\
Local road & 30 & 94 & 28.20 & 31 & 32.98 & 96 & 30.79 & 43 & 44.79 \\
Total & $/$ & 617 & $/$ & 63 & 10.21 & 699 & $/$ & 97 & 13.88 \\
\hline
\end{tabular}

Note: The data are obtained from the radar gun survey.

A total of 617 speed samples of battery-electric vehicles were obtained, of which the speeding samples accounted for $10.21 \%$. In addition, there were 699 private car speed samples, of which the speeding samples accounted for $13.88 \%$. A comparison of the measured average speed of battery-electric taxis and private cars under different speed limits is shown in Figure 3a, and a comparative analysis of the speeding extent is shown in Figure 3b. It can be seen in Figure 3 that the measured average speed of battery-electric taxis is greater than that of the private cars at the condition of a speed limit higher than $100 \mathrm{~km} / \mathrm{h}$. As shown in Table 3, in order to maximize the profitability, the percentage of speeding battery-electric taxis on urban roads varies from $7.43 \%$ to $32.98 \%$, whereas the speeding ratio of the private cars on local roads is $44.79 \%$. The speeding phenomenon on local roads is more serious than that on major arteries and minor arterial roads. Due to the 
lack of traffic signage, monitoring equipment, and supervision, the proportion of speeding vehicles on local roads is more than $30 \%$. By comparing the speeds that are over the speed limit, it can be found that the speeding extent of battery-electric vehicles is greater.



(a)

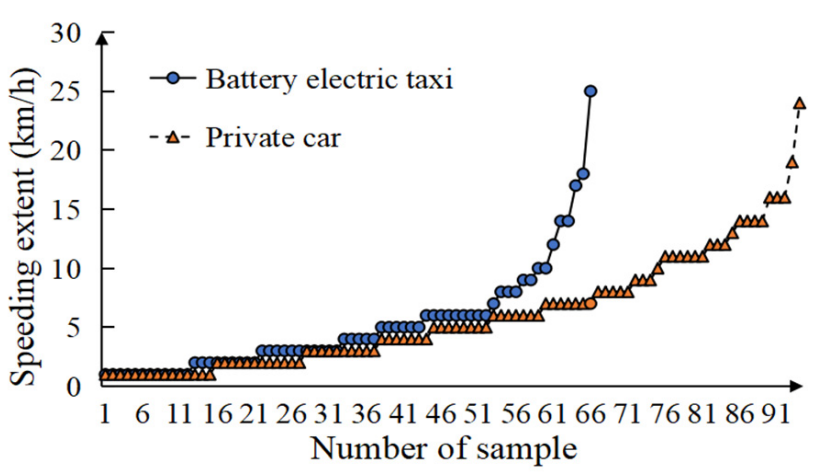

(b)

Figure 3. Comparison analyses of measured speeds. (a) Comparison analysis of measured mean speeds; (b) Comparison analysis of speeding extent.

\section{A Method for the Operating Safety Assessment of Battery-Electric Taxis}

Based on the speed parameters, combined with the time and space characteristics, the operating safety evaluation index system of battery-electric taxis is proposed, as shown in Figure 4. The proposed index system includes six temporal-speed indicators and nine spatial-speed indicators. The temporal-related indicators include the average operating speed, acceleration, and deceleration on weekdays and weekends. The spatial-speed indicators include instantaneous speed, speeding ratio, and speeding ratio on major arterial roads, minor arterial roads, and local roads.

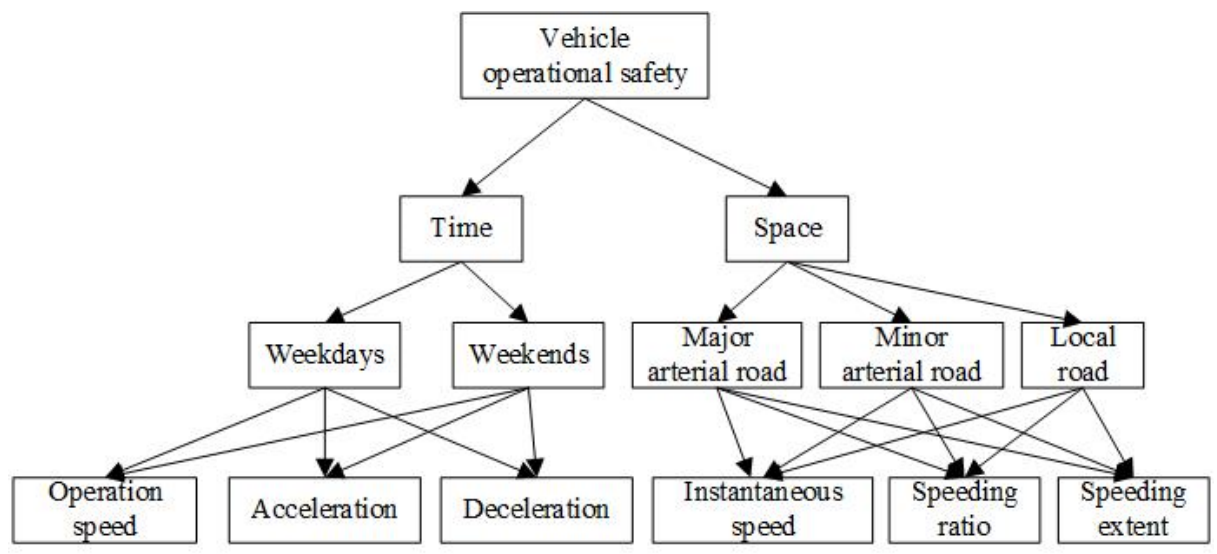

Figure 4. Operating safety evaluation index system of battery-electric taxis based on speed parameters.

To obtain an effective assessment result, the multi-attribute decision making (MADM) methods [23] are adopted as a framework to account for the impacts of the proposed 15 speed parameters. Among the MADM methods, the most commonly used methods are based on the assumption that an aggregating function indicates the closeness to the ideal, such as TOPSIS methods and VIKOR methods [24,25].

The basic idea of the TOPSIS (Technique for Order Preference by Similarity to an Ideal Object) methods is comparing the similarity of each evaluation object to the ideal and anti-ideal objects. On the other hand, the VIKOR (VIsekriterijumsko KOmpromisno Rangiranjie) methods have been proposed to provide solutions to discrete multiple impact factors that include conflicting, contradicting, and non-commensurable impact factors. 
In the research, since the speed parameters of vehicles are not commensurable, the VIKOR methods $[26,27]$ are adopted to rank the safety performances of battery-electric taxis, conventional taxis, and private cars with 15 speed parameters. To account for the impacts and influence of temporal-speed parameters and spatial-speed parameters, simultaneously, based on the VIKOR methods, a multi-layer entropy-weighted VIKOR (MEW-VIKOR) method is employed to evaluate the safety performances of the electric taxis [28].

Supposing the set of speed parameters is $C=\left\{c_{1}, c_{2}, \ldots, c_{m}\right\}$, then the normalized decision matrix can be represented as:

$$
\begin{gathered}
x_{i j}=\frac{c_{i j}}{\sqrt{\sum_{i=1}^{n}\left(c_{i j}\right)^{2}}} \\
\mathbf{D}=\left[\begin{array}{cccc}
x_{11} & x_{12} & \cdots & x_{1 m} \\
x_{21} & x_{22} & \cdots & x_{2 m} \\
\vdots & \vdots & \ddots & \vdots \\
x_{n 1} & x_{n 2} & \cdots & x_{n n}
\end{array}\right]
\end{gathered}
$$

where $c_{i j}$ is the value of $j$ th speed parameter for the $i$ th type of vehicles, $i=1,2, \ldots, n ; j=1$, $2, \ldots, m$ and $x_{i j}$ is the normalized value of $c_{i j}$.

The entropy-weighted (EW) method is used to calculate the weight of each speed parameter to overcome the weakness of the VIKOR method, which uses the subjective weight values [29]. The information entropy weight of the $j$ th speed parameter of the developed entropy-weighted VIKOR (MEW-VIKOR) can be calculated as:

$$
w_{j}=\frac{1+\frac{1}{\ln n} \sum_{i}^{n} e_{i j}}{\sum_{j=1}^{3}\left(1+\frac{1}{\ln n} \sum_{i}^{n} e_{i j}\right)}
$$

where $n$ is the number of vehicles, $e_{i j}$ is the information entropy of $j$ th speed parameter for the $i$ th type of vehicles. The $e_{i j}$ can be calculated as:

$$
e_{i j}=\frac{x_{i j}}{\sum_{i=1}^{n} x_{i j}} \ln \left(\frac{x_{i j}}{\sum_{i=1}^{n} x_{i j}}\right)
$$

The utility index and regret measurements for all vehicles can be calculated as:

$$
\begin{aligned}
U_{i} & =\sum_{j=1}^{m} w_{j}\left(x_{j}^{*}-x_{i j}\right) /\left(x_{j}^{*}-x_{j}^{-}\right) \\
R_{i} & =\max _{j}\left[w_{j}\left(x_{j}^{*}-x_{i j}\right)\left(x_{j}^{*}-x_{j}^{-}\right)\right]
\end{aligned}
$$

where $U_{i}$ is the utility indicator; $R_{i}$ is the regret indicator; $x_{j}^{*}$ is the ideal object, $x_{j}^{*}=\max _{i}$ $x_{i j} ; x_{j}$ - is the negative object, $x_{j^{-}}=\min _{i} x_{i j}$.

Let $U^{*}=\min _{i} U_{i}, U-=\max _{i} U_{i}, R^{*}=\min _{i} R_{i}, R-=\max _{i} R_{i}$, the EW-VIKOR indicator of safety of the $i$ th type of vehicles can be calculated as follows:

$$
P_{i}=1-\alpha\left(U_{i}-U^{*}\right) /\left(U^{-}-U^{*}\right)+(1-\alpha)\left(R_{i}-R^{*}\right) /\left(R^{-}-R^{*}\right)
$$

where $\alpha$ is a weight for the group solution of maximum utility, whereas $1-\alpha$ is the weight of each regret, here $\alpha=0.5$.

The greater value of $P_{i}$ indicates the more dangerous condition In other words, the evaluated vehicles can be ordered and arranged by the value of $P_{i}$. When $P_{i}=1$, the vehicle 
is the most unsafe and dangerous, and more countermeasures and policies should be proposed and implemented for safety improvements. Otherwise, if $P_{i}=0$, the vehicle is the safest and some strategies and policy methods should be given attention to ensure that the vehicles operating condition stays at a certain level.

To comprehensively address the safety issues of the electrical taxi, especially the collision with pedestrians, an assumption of a collision with an assumed speed is conducted after the safety evaluation and ranking.

\section{Empirical Research}

Combined with the GPS trajectory data and measured data from the handheld radar guns, 15 speed indicators were collected in both time and space dimensions to rank the operating safety of battery-electric taxis. Based on the proposed operating safety evaluation method, the operating safety of battery-electric taxis, conventional taxis, and private cars are ranked. The ranking results show that the score of battery-electric taxis is 0.62 , conventional taxis is 0.50 , and private cars is 0.14 . Based on the speed parameters, the risk of battery-electric taxis is the highest, followed by the conventional taxis, and the last being the private cars. Taxi drivers are often characterised by unsafe driving behaviors in terms of speed control, due to their familiarity with road conditions and the presence of overlong driving hours. Although the score of the conventional taxi is lower than that of the battery-electric taxi, showing a certain degree of safety, the difference in the ranking results is not significant.

Using the speed-distance formula, incorporated with the calculated average deceleration parameters, the braking distance $(\mathrm{m})$ is calculated under different speed conditions, as shown in Figure 5. It can be seen from Figure 5, at a driving speed of $40 \mathrm{~km} / \mathrm{h}$, the battery-electric taxi needs $46.83 \mathrm{~m}$ to $55.51 \mathrm{~m}$ to stop, at a driving speed of $60 \mathrm{~km} / \mathrm{h}$, the braking distance of the battery-electric taxi is $105.38 \mathrm{~m}$ to $124.90 \mathrm{~m}$, and when the driving speed is $80 \mathrm{~km} / \mathrm{h}$, the braking distance of the battery-electric taxi is $187.34 \mathrm{~m}$ to $222.04 \mathrm{~m}$. With the increase in speed, the braking distance will increase at a higher rate.

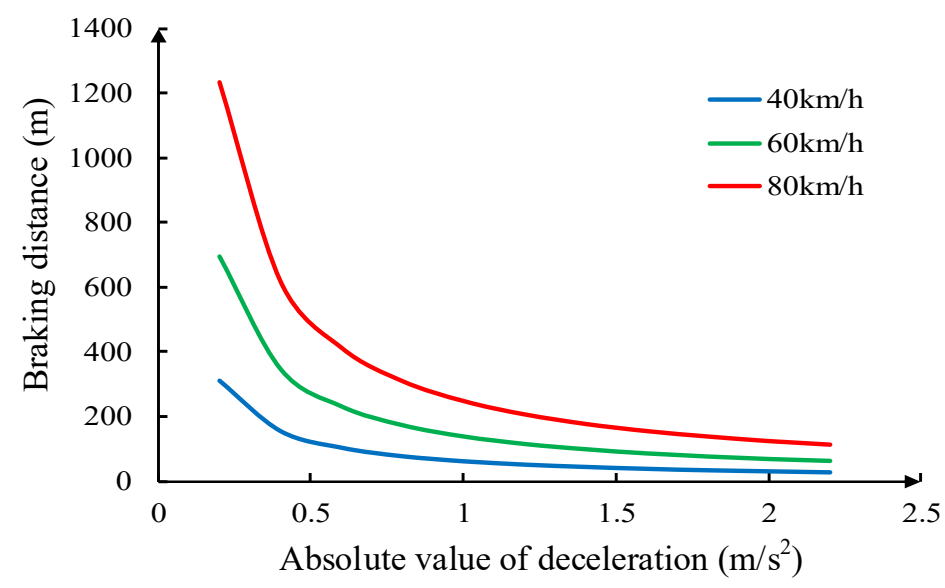

Figure 5. The relationship between the braking distance and the braking deceleration of the batteryelectric taxis.

Collision kinetic theorem is a classical topic in road safety research [30,31]. In order to further analyze the braking performance and safety of battery-electric taxis, combined with the formula of kinetic energy theorem, the collision kinetic energy of adult men with a certain mass when they are hit by battery-electric taxis under different speed conditions is analyzed. The calculation formula is: $\mathrm{E}=m \cdot \Delta v^{2}$.

Assume that the mass of the adult male is $\mathrm{m}=75 \mathrm{~kg}, \Delta v=v_{\text {man }}-v_{\text {vehicle, }}$, and take the direction of the person flying out as the positive direction. Considering that before the vehicle hits the person, the person stands in front of the vehicle. When the vehicle hits the person, the impacted person will fly out in the positive direction at the speed of $v_{\text {man }}$, thus 
the speed variation $\Delta v$ of the entire impact process is equal to the fly out speed $v_{\text {man }}$ minus the speed of the person relative to the vehicle. That is, from the driving speed of the vehicle $v_{\text {vehicle }}$, substituted into the formula of kinetic energy change, the collision kinetic energy under different speeds can be obtained. Assuming that the person is hit and flies out at a speed of $20 \mathrm{~km} / \mathrm{h}$, the calculation results are shown in Table 4 .

Table 4. Comparison of collision kinetic energy and external forces of battery-electric taxi at a given speed.

\begin{tabular}{|c|c|c|c|}
\hline \multirow{2}{*}{ Results } & \multicolumn{3}{|c|}{ Given Speed } \\
\hline & $40 \mathrm{~km} / \mathrm{h}$ & $60 \mathrm{~km} / \mathrm{h}$ & $80 \mathrm{~km} / \mathrm{h}$ \\
\hline Collision kinetic energy (kJ) & 20.83 & 37.04 & 57.87 \\
\hline Collision force (kN) & 6.25 & 8.33 & 10.42 \\
\hline
\end{tabular}

The severity of injury was measured by the external force of the human body. According to exploratory experiments conducted on various subjects, a person on a rollercoaster experiences about $6 \mathrm{~g}$ of pressure, but for a short duration. A fighter pilot in a compression suit can withstand 8 or $9 \mathrm{~g}$ of pressure. In contrast, the force of eight gravitation accelerations is enough to kill an unprotected pedestrian. Based on the above considerations, using the formula of Newton's second law under different speed conditions: $F=m \cdot a$. Assume that the contact time between the person and the battery-electric taxi is $0.2 \mathrm{~s}$ and that the person will fly out at $20 \mathrm{~km} / \mathrm{h}$ after being hit; Table 4 shows the comparative analysis of the external impact $(\mathrm{KN})$ of an adult man with $\mathrm{m}=75 \mathrm{~kg}$. It can be seen from Table 4 that when a battery-electric taxi hits a pedestrian at a speed of $40 \mathrm{~km} / \mathrm{h}$, the acceleration value has exceeded what the human body can withstand, thus making it easy to cause a fatal accident. This is also an important reason as to why accidents involving battery-electric taxis have a higher fatality rate.

\section{Conclusions}

The battery-electric taxis have a large mass, low operating noise, and a higher speed. Meanwhile, the drivers have an extensive educational background and low safety awareness, which leads to more safety risks. In this paper, the driving and speed characteristics of battery-electric taxis, conventional taxis, and private cars were compared and analyzed through conducting a GPS trajectory survey and a cross-section traffic flow parameter survey. An evaluation index system based on spatio-temporal speed parameters is proposed, and the MEW-VIKOR safety evaluation method for the operating safety of battery-electric taxis is developed. The research results show that the operating speed of battery-electric taxis is significantly higher than that of conventional taxis on weekdays and weekends, and there is a relatively common speeding phenomenon on urban local roads. The proposed safety evaluation index system that is based on the spatio-temporal parameters and the MEW-VIKOR evaluation method can effectively evaluate the operating safety of batteryelectric taxis. In addition, the ranking results show that, based on the spatio-temporal speed parameters, the operating safety of battery-electric taxis is lower than that of conventional taxis and private cars.

Based on the analyses of the operating speed of battery-electric taxis, it is clear that the speeding phenomenon is common, expecially on the local roads. In order to ensure traffic safety, create a good traffic environment, and build a better traffic order, according to the ideas and principles of speed limits for medium and large trucks in the United States and TianJin, it is recommended that a separate speed limit should be imposed for the battery-electric taxis at night (10:00 p.m.-7:00 a.m. of the next day) in the accident-prone areas. This will improve the vigilance and awareness of taxi drivers, reduce the likelihood and severity of accidents, and mitigate the safety risks.

Limited by the data and methodologies, only the operating safety of the electrical taxis was analyzed in the research. In the future, with more data, such as the driving 
characteristics, and more sophisticated modeling approaches, the safety evaluation of battery-electrical vehicles should be comprehensively performed and investigated.

Author Contributions: Conceptualization, C.D. and C.S.; methodology, X.M. and Y.L.; validation, X.M. and Y.L.; writing-original draft preparation, N.L. and B.F.; writing-review and editing, N.L. and C.D.; supervision, C.D. All authors have read and agreed to the published version of the manuscript.

Funding: This research was supported by funding provided by the National Key R\&D Program of China (grant number 2019YFF0301400).

Institutional Review Board Statement: Not applicable.

Informed Consent Statement: Not applicable.

Data Availability Statement: These data will be available based on requesting to the corresponding author.

Acknowledgments: We thank the committee of GITSS for recommending the manuscript be submitted to Sustainability.

Conflicts of Interest: The authors declare no conflict of interest.

\section{References}

1. Jochem, P.; Doll, C.; Fochitner, W. External costs of electric vehicles. Transp. Res. Part D Transp. Environ. 2016, 42, 60-76. [CrossRef]

2. Declerck, Q.; Vanlier, T.; Messagie, M.; Macharis, C.; Van Mierlo, J.; Vanhaverbeke, L. Total Cost for Society: A persona-based analysis of electric and conventional vehicles. Transp. Res. Part D Transp. Environ. 2018, 64, 90-110. [CrossRef]

3. Ahmadi, P. Environmental impacts and behavioral drivers of deep decarbonization for transportation through electric vehicles. J. Clean. Prod. 2019, 225, 1209-1219. [CrossRef]

4. Lukjanow, S.; Zielinski, W. A concept of the assessment of electric vehicles' operational Safety. In Proceedings of the Scientific Conference on Automotive Vehicles and Combustion Engines, Krakow, Poland, 22-23 September 2016.

5. Zieinski, W.; Lukjanow, S. Examination of selected electric vehicles in respect of optional safety. In Proceedings of the International Scientific Automotive Conference on Automotive Vehicles and Combustion Engines, Cracow, Poland, 13-14 September 2018; pp. 13-14.

6. Karaaslan, E.; Noori, M.; Lee, J. Modeling the effect of electric vehicle adoption on pedestrian traffic safety: An agent-based approach. Transport. Res. C-Emer. 2018, 93, 198-210. [CrossRef]

7. Frlić Sekulić, N.; Blagojević, I.; Popović, V.; Janković, S. Development of pedestrian alert system for use in electric vehicles. Teh. Vjesn. 2019, 26, 1614-1619.

8. Lee, S.K.; Lee, S.M.; Shin, T. Objective evaluation of the sound quality of the warning sound of electric vehicles with a consideration of the masking effect: Annoyance and detectability. Int. J. Auto. Tech. Kor. 2017, 18, 699-705. [CrossRef]

9. Chen, R.; Choi, K.S.; Daniello, A.; Gabler, H. An analysis of hybrid and electric vehicle crashes in the U.S. In Proceedings of the 24th International Technical Conference on the Enhanced Safety of Vehicles, Gothenburg, Sweden; 2015.

10. Chu, W.; Zhou, L. Analysis and suggestions on the hidden dangers of pure electric vehicle traffic safety. Rd Traffic Manag. 2020, 4, 32-33.

11. Ye, L.; Zhao, Y.; Liu, W. Safety analysis and research of electric vehicle. J. Southwest Aut. Info. 2016, 8, 5-9.

12. Wang, X.; Niu, L.; Huang, Y.; Jiang, Y. Research on evaluation system of electric and safety performance of electric vehicle charger. Chin. J. Power Sources 2014, 38, 734-736.

13. Xu, X.; Liu, Z.; Li, Y. Multi-level fuzzy evaluation method of car comprehensive performance. J. Changsha Univ. Sci. Technol. Nat. Sci. 2006, 4, 59-62.

14. Cao, L.; Xie, F. Research on electric vehicle power system and vehicle safety performance. Chin. J. Auto. Eng. 2003, 2, 42-44.

15. Mukiyt, A.; Wang, Y.; Xiao, L.; Dong, H.; Huang, G. Electric vehicle safety evaluation based on fuzzy analytic hierarchy process. Sta. Sci. 2018, 11, 45-52.

16. Zhang, J.; Li, X.; Chen, X. Research on the comprehensive evaluation method of pure electric vehicle performance. Auto Parts 2020, 3, 26-30.

17. Lu, Y.; Li, K.; Han, X.; Feng, X.; Chu, Z.; Lu, L.; Huang, P.; Zhang, Z.; Zhang, Y.; Yin, F.; et al. A method of cell-to-cell variation evaluation for battery packs in electric vehicles with charging cloud data. ETransportation 2020, 6, 100077. [CrossRef]

18. Concha, P.M.; Velez, P.; Lafoz, M.; Arribas, J.R. Passenger exposure to magnetic fields due to the batteries of an electric vehicle. IEEE Trans. Veh. Technol. 2016, 65, 4564-4571. [CrossRef]

19. Zhu, C.; Lu, F.; Zhang, H. A real-time battery thermal management strategy for connected and automated hybrid electric vehicles (CAHEVs) based on iterative dynamic programming. IEEE Trans. Veh. Technol. 2018, 67, 8077-8084. [CrossRef]

20. Aarts, L.; Van, S.I. Driving speed and the risk of road crashes: A review. Acci. Anal. Prev. 2006, 38, 215-224. [CrossRef] [PubMed] 
21. Zheng, Y.; Ran, B.; Qu, X.; Zhang, J.; Lin, Y. Cooperative lane changing strategies to improve traffic operation and safety nearby freeway off-ramps in a connected and automated vehicles environment. IEEE Trans. Intell. Transp. Syst. 2019, 21, 4605-4614. [CrossRef]

22. Zhang, B.; Chen, S.; Ma, Y.; Li, T.; Tang, K. Analysis on spatio-temporal urban mobility based on online car-hailing data. J. Transp. Geogr. 2020, 82, 102568. [CrossRef]

23. Opricovic, S.; Tzeng, G.H. Compromise solution by MCDM methods: A comparative analysis of VIKOR and TOPSIS. Eur. J. Ope. Res. 2004, 156, 445-455. [CrossRef]

24. Liu, Z.; Jiang, C.; Wang, J.; Yu, H. The node importance in actual complex networks based on a multi-attribute ranking method. Knowl. Based Syst. 2016, 84, 56-66. [CrossRef]

25. Ploskas, N.; Papathanasiou, J. A decision support system for multiple criteria alternative ranking using TOPSIS and VIKOR in fuzzy and nonfuzzy environments. Fuzzy Sets Syst. 2019, 377, 1-30. [CrossRef]

26. Yuan, Y.; Guan, T.; Yan, X.; Li, Y. Supplier selection decision model based on hybrid VIKOR method. Control Decis. 2014, 29, 551-560.

27. Zhou, Q.; Wang, Q. Research on low-carbon supplier selection method based on intuitionistic fuzzy sets and VIKOR. Sci. Techno. Manag. Res. 2017, 37, 233-237.

28. Mi, X.Y.; Shao, C.F.; Dong, C.J.; Zhuge, C.X.; Zheng, Y. A Framework for intersection traffic safety screening with the implementation of complex network theory. J. Adv. Transport. 2020, 2020, 8824447. [CrossRef]

29. Fan, Z.; Zhao, X. Subjective and objective weighting method for determining weights in multi-attribute decision-making. J. Manag. Sci. Eng. 1997, 4, 89-93.

30. Li, D.; Song, Y.; Sze, N.N.; Li, Y.; Miwa, T.; Yamamoto, T. An alternative closed-form crash severity model with the non-identical, heavy-tailed, and asymmetric properties. Accid. Anal. Prev. 2021, 158, 106192. [CrossRef]

31. Guo, Y.; Sayed, T.; Essa, M. Real-time conflict-based Bayesian Tobit models for safety evaluation of signalized intersections. Accid. Anal. Prev. 2020, 144, 105660. [CrossRef] 